\section{Asbestos-Related Research: First Objectivity then Conclusions}

Keywords: Chrysotile; Amphiboles; Asbestos; Mesothelioma; Lung cancer

\begin{abstract}
Asbestos-related risks have been extrapolated from the past when high-dose occupational exposures were frequent. The linear no-threshold dose-response pattern has been assumed, but its applicability to low-dose asbestos exposures has never been proven. Morphologically, malignant mesothelioma can resemble various cancers. There are diagnostic algorithms; however, a tumor diagnosed by standard methods as mesothelioma is not a welldefined entity, in all cases substantially different from other cancers. Well-aimed search and screening effect have probably contributed to the enhanced incidence of mesothelioma and other asbestosrelated diseases in exposed populations. Asbestos-related disease have been extensively studied in Russia. The prevailing view is that, if all precautions are observed, modern technologies of asbestos production and processing are acceptably safe, whereas bans and prohibitions applied by some countries are excessive. At the same time, there are economic interests to promote chrysotile. Biases due to industrial interests have compromised the objectivity of some asbestosrelated reports. In the author's opinion, the "all fibers equal" basis of official regulations can be accepted provisionally pending objective and reliable evidence on toxicity of different asbestos types and manmade substitutes. On the basis of independent scientific data, the bans and restrictions on asbestos in some countries should be re-examined and potentially revised. Any permit of continued production or use of asbestos materials must be coupled with regulations and efficient measures to prevent environmental contamination associated even with minimal additional risks.
\end{abstract}

Asbestos-related risks have been estimated on the basis of extrapolations from the past, when high-dose occupational and non-occupational exposures were frequent. Evolution of the concept of low- vs. high-dose asbestos exposures can be illustrated by the gradual decline of the Permissible Exposure Limit (PEL) adopted by the Occupational Safety and Health Administration (OSHA): 1971$12 \mathrm{f} / \mathrm{cc}$ of air as a $8 \mathrm{~h}$ time weighed average; 1972- 5; 1976-2; in 1986, the current PEL for asbestos in the workplace was established: $0.1 \mathrm{f} /$ cc $[1,2]$. A well-known asbestos contamination was the "Mr Fluffy" incident in Australia (1960-70s), where loose asbestos was used for insulation of houses [3]. In Russia, corrugated asbestos board has been broadly used for roofing being often sawed by hand; asbestoscement pipes are routinely used for drinking water distribution (Figure 1) [4]. Other asbestos-containing materials (flat sheets, asbestos paper, cloth, gaskets, etc.) are broadly used now as before. The linear no-threshold dose-response pattern has generally been assumed for the low exposure levels, but its applicability to low-dose asbestos exposures has never been proven. In some places, asbestos fibers are present in the natural environment due to erosion of surface deposits. For example, the fibers were detected in the lungs of $63.6 \%$ deceased individuals from the general population [5]. Inhalation and discharge of the fibers occur normally [6], probably within a dynamic equilibrium. Existence of a threshold for the exposure to mineral fibers has not been reported, but may be assumed by analogy with other environmental factors that have induced evolutionary

\section{Environmental} Studies

\author{
Sergei V. Jargin* \\ Department of Pathology, People's Friendship University of Russia, \\ Russia \\ *Address for Correspondence \\ Sergei V. Jargin, Department of Pathology, People's Friendship \\ University of Russia, Clementovski per 6-82, 115184 Moscow, Russia, \\ Tel: +7 495 9516788; E-mail: sjargin@mail.ru \\ Submission: 12 October, 2015 \\ Accepted: 01 December, 2015 \\ Published: 07 December, 2015 \\ Copyright: (๑) 2015 Jargin SV. This is an open access article distributed \\ under the Creative Commons Attribution License, which permits \\ unrestricted use, distribution, and reproduction in any medium, provided \\ the original work is properly cited.
}

adaptation [7,8]. Further research into non-linear, threshold cancer risk models is warranted both for asbestos [9], and for its substitutes.

Apparently, the screening effect has contributed to the enhanced registered incidence of asbestos-related diseases in exposed populations and an over estimation of the dose-response relationship. In particular, mesothelioma (Mt) was sought among exposed people and correspondingly more often found. Malignant Mt is an uncommon neoplasm developed by a small percentage of people exposed to asbestos. It can be spontaneous, or occur when asbestos fibers are present in the pulmonary or pleural tissues. Apart from asbestos, other potential etiologic factors of malignant $\mathrm{Mt}$ are mineral (erionite) and artificial (ceramic, carbone nanotubes) fibers [10-13], virus SV40, radiation, and genetic predisposition [14-17] (Figure 2).

Misclassification of disease is a problem for several of the cancer

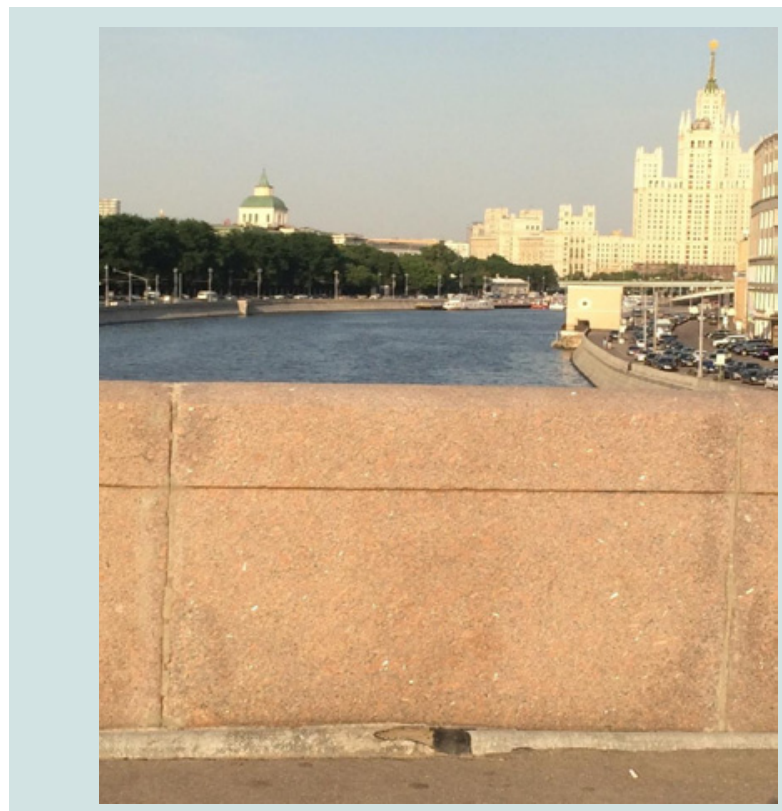

Figure 1: Partly destroyed asbestos cement drain-pipe in Moscow. 


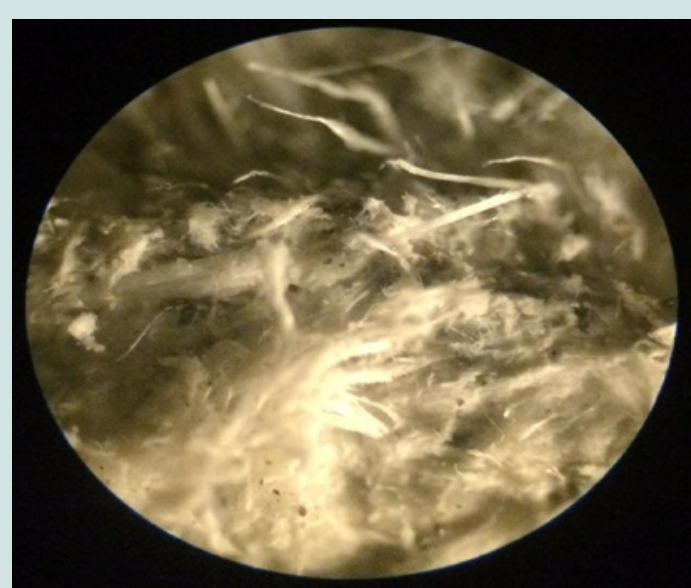

Figure 2: Reflected light microscopy of the fracture surface of the asbestos cement pipe shown on Figure 1. Fibers are visible. $X 56$

sites. This is particularly true for mesothelioma, which did not have diagnostic category in the ICD system until the $10^{\text {th }}$ review was initiated in 1999 [18]. Histologically, malignant Mt can resemble various cancers and the lack of accurate biomarkers makes diagnosis challenging [19]. Some Mt studies may have mistakenly included tumors having similar morphology [17]. Metastatic cancers can undergo structural transformation, becoming histologically similar to malignant Mt [20]. The morphological differential diagnosis is different depending on Mt subtype [21]. There are standard diagnostic algorithms-a tumor diagnosed as malignant Mt through standard methods is not a well-defined entity, in all cases substantially different from other cancers. Cytogenetic studies found out that malignant $\mathrm{Mt}$ has complex and even chaotic chromosomal aberrations [14,22,23]. No marker discriminates well between Mt and other cancers [19,24], which, in conjunction with uncertainty about progenitor cells [14], makes the demarcation of $\mathrm{Mt}$ as an entity indistinct. Mesothelin and osteopontin have been considered promising markers, but both have limitations $[18,25,26]$. Although several studies indicated that mesothelin is useful for screening, other evidence indicates that this marker has a considerable false-positivity rate [27], being insufficiently sensitive for early diagnostics [28]. Osteopontin serum concentration is not regarded to be an adequate marker because it lacks specificity in differentiation between Mt and metastatic carcinoma [29]. Data on microRNA down regulation in $\mathrm{Mt}$, compared to lung cancer [30,31], may be promising for demarcation, but since microRNAs are often deregulated in different cancers [31,32], the specificity of this marker is questionable, and the possibility of misclassifications cannot be excluded [33]. The validity of biomarkers is sometimes over estimated due to the push by researchers, institutions and sponsors for groundbreaking research [28]. In Russia, certain studies of reportedly specific markers, e.g. of cell damage by alcohol, were never confirmed by later research, and resulted from organ biopsies performed without sufficient clinical indications [34].

Furthermore, biases can be encountered in Mt and asbestos research, e.g. the detection of small amounts of fiber in pulmonary or pleural tissues automatically attributing the neoplasm to asbestos [35]. As mentioned earlier, asbestos fibers are not infrequent in pulmonary tissues of people without any professional exposure [5]. Some studies rely on work histories of questionable reliability, interviews with relatives of deceased patients, etc. Biases due to industrial interests and litigation may further compromise objectivity [35].

Asbestos-related diseases have been extensively studied in Russia. The prevailing view is that, if all precautions are observed, modern technologies of asbestos production and processing are acceptably safe, whereas bans and prohibitions applied by some countries are excessive [36,37]. Some scientists admitted that the concept of much higher carcinogenicity of the amphiboles compared to chrysotile has not been confirmed [38]. There are also strong economic interests to promote chrysotile. Accordingly, statements in favor of chrysotile (sometimes without references) can be encountered [39,40]: "Chrysotile fibers are easily dissolved and discharged" [40]. Papers by David Bernstein agree with some Russian reports:

- Following short-term exposure the longer chrysotile fibers rapidly clear from the lung and are not observed in the pleural cavity. In contrast, short-term exposure to amphibole asbestos results quickly in the initiation of a pathological response in the lung and the pleural cavity [41];

- Chrysotile fibers are rapidly cleared from the lung in marked contrast to amphibole fibers which persist [42].

It should be noticed that the fiber presence is essential in pulmonary and pleural tissues, not in the cavity. Given the possibility of a post-depositional movement of chrysotile fibers from the lung to the pleura [43-48], such statements are an over simplification. The rate of asbestos retention cannot be characterized only on the basis of measurements of fiber contents in pulmonary tissues - The proportion of chrysotile fibers (as opposed to the amphiboles) was shown to be higher in parietal pleura than in lung tissue [43]. Moreover, the accelerated clearance of chrysotile from the lung can be partly caused by a disintegration of chrysotile (but not amphibole) fibers into thin fibrils, which are more difficult to identify. The total number of fibrils would increase due to fiber splitting [47,49,50], possibly together with the carcinogenic effect, as the split fibrils can move to the pleura $[45,47,48]$. Asbestos fibers have been identified in the pleura by autopsy, chrysotile being the predominant asbestos form found in pleural plaques [51] and pleural/mesothelial tissues in general $[46,52]$. In a singular contradicting report amphibole fibers outnumbered chrysotile ones in anthracotic "black spots" in the parietal pleura sampled during thoracoscopy from all 14 studied individuals [53]. Chrysotile may undergo not only longitudinal splitting but also breakage into shorter fibers, which may be cleared more readily [18]; however, short chrysotile fibers were reported to prevail in the pleura $[48,52]$. The paradigm of fiber migration to the pleura agrees with the primary affect of asbestos-related Mt usually occurring in the parietal rather than visceral pleura [54].

Statements and conclusions by Bernstein et al. are supported by numerous self-references $[41,55]$. It has been commented, however, that Bernstein's experimental findings contradict results obtained by independent researchers and can only be explained by an aggressive pre-treatment of fibers, inducing faults and fragility in the fibers' structure, leading to their hydration and breaking [56]. Note that decomposition by acids does not necessarily mean easy solubility in living tissues. Different types of fibers were tested for solubility 
in the Gamble's solution, which is similar in composition to lung fluid except for organic components [57], and both chrysotile and crocidolite had very low solubility. The dissolution values ranged from a few nanograms of dissolved silicon per square centimeter of fiber surface (chrysotile and crocidolite) to several thousands of $\mathrm{ng} \mathrm{cm}^{-2}$ (glass wools). On the contrary, aramide and carbon fibers were demonstrated to be practically insoluble [57]. It means that certain artificial fibers, proposed as asbestos substitutes, are more biopersistent than asbestos fiber. The study [57] was cited in [55]; but the results were not discussed.

Chrysotile was demonstrated to cause chromosomal aberrations and to induce pre-neoplastic transformations of cells in vitro $[58,59]$. In certain animal experiments, the amphiboles and chrysotile were shown to be nearly equally carcinogenic for the induction of both Mt $[50,58,60,61]$ and lung cancer $[62,63]$. Chrysotile was found to be even more carcinogenic than amphiboles in [60], where it was pointed out: "There was no evidence of either less carcinogenicity or less asbestosis in the groups exposed to chrysotile than those exposed to the amphiboles" [60]. Technical details of the study [60] were discussed in [55] but not this essential result. In [64], chrysotile asbestos produced far more lung fibrosis and pulmonary neoplasia than the amphiboles, which was explained by a relatively high fraction of fibers longer than $20 \mu \mathrm{m}$ in the chrysotile dust used in this experiment [18]. It is known that carcinogenic effect depends on the fiber dimensions (length, diameter) $[10,65,66]$. A comprehensive review [46], not cited in [41,55], concluded that animal studies indicate an approximately equal risk for all asbestos fibers: "Even if one accepts the argument that chrysotile asbestos does not induce Mt (which we do not), the risk of lung cancer (and asbestosis) cannot be dismissed, and chrysotile appears to be just as potent a lung carcinogen as the other forms of asbestos" [46].

Furthermore, it was commented that "Bernstein and colleagues completely ignored the human lung burden studies that refute their conclusion about the short biopersistence of chrysotile"; more details and references are in [67]. Statistically significant doseresponse relationships between the odds ratios for mesothelioma and concentrations of asbestos fibers of different types were reported [68]. In particular, in the group with only chrysotile fiber in the lungs, a statistically significant trend of an increasing relative risk of mesothelioma with increasing fiber content was demonstrated [68]. This paper was not cited in $[41,55]$. Further reports $[69,70]$ on persistence of chrysotile fibers in the lungs and/or their possible association with Mt and lung cancer, not cited in [41,55], were discussed in [67]. In the author reply [71], the arguments from [67] have not been adequately responded, being dismissed by a declaration that the studies $[68,69]$ "appear to support the concepts put forward by Bernstein et al." followed by self-references [71]. Other reports and reviews [43-48,51,56,58,63,72-75], not supporting the authors' concept, are also not cited in the voluminous reviews $[41,55]$. Another example: Bernstein et al. cite a rather nondescript phrase from the review "Mesothelioma from chrysotile asbestos" $[55,76]$ that chrysotile is an "exclusive or overwhelming fiber exposure", disregarding the main conclusion: "Chrysotile asbestos, along with all other types of asbestos, has caused mesothelioma" [76]. It was reasonably concluded that by failing to analyze or even mention contradicting data, Bernstein et al. did not provide an objective analysis, and have created the impression that they have published a document to support the interests of chrysotile producers $[56,67]$. It should be added that some papers by Bernstein et al. sound remarkably similar to Russian publications obviously promoting chrysotile $[39,40]$.

Association of Mt with crocidolite as opposed to chrysotile was advocated by J. Christopher Wagner, mainly on the basis of epidemiologic data, propagating the difference between white (chrysotile) and blue (crocidolite) asbestos [77], although it was partly at variance with his own experiments [60,61]. Wagner's epidemiological data were from crocidolite-exposed workers, where the relatively large number of registered $\mathrm{Mt}$ cases could have been caused by a well-aimed search and higher exposures to asbestos during the 1950s and possibly earlier given long latency period of malignant Mt. The high incidence of Mt in workers exposed to crocidolite could also have been related to a lack of control for potential differences in exposure levels [78]. The screening-effect has probably influenced results also of other studies of amphibole-exposed workers. Reported associations between the Mt incidence and the time of a first exposure, duration of exposure and cumulative exposure [79] can be explained by dose-related differences in medical surveillance and self-reporting, a mechanism discussed in the context of radiation-related conditions [80]. The evidence in favor of crocidolite toxicity based e.g. on the Wittenoom cohort studies seems to be compelling [81-83], although the number of deaths with mesothelioma in men in the period 1987 to 2008 remained similar to the lowest predictions (the number of Mt in the past 8 years was higher than predicted - 74 vs. 63) [83], while genetic predisposition was discussed along with asbestos as an etiologic factor of Mt [84]. There is considerable evidence that the risk of Mt is enhanced after exposure to chrysotile without amphibole admixture $[46,48,72-76,85]$. There has been also an alternate view $[86,87]$ e.g. that that the exposure-specific risk of Mt from three commercial asbestos types (chrysotile, amosite and crocidolite) is broadly in the ratio 1:100:500 [88]. However, in a later publication by the same authors, the proportion 1:5:10 is discussed; and it is acknowledged that recent evidence had strengthened the case for the proposition that the per-fiber risk of mesothelioma from chrysotile in textile plants is greater than it is in mines [89]. According to $[46,62,63]$, there is no epidemiological or toxicological evidence that chrysotile is less potent than other forms of asbestos for induction of lung cancer, which is essential because of much higher prevalence of lung cancer. It has been suggested that the difference between chrysotile and amphibole fibers for lung cancer is between 1:10 and 1:50 [88]. The same researchers [88] acknowledged that, in view of the evidence that all three asbestos types have produced a similar level of lung tumors in animal inhalation experiments [46], it is problematic to reconcile the animal and human data. The proposed explanation was that "in humans chrysotile (cleared in months) might have less effect than the amphibole fibers (cleared in years)" [88]. It was the purpose of this review to question the latter argument (chrysotile clearance from the lung may be partly explained by fiber splitting and migration to the pleura) and objectivity of human studies in general (unsharp delineation of $\mathrm{Mt}$ as an entity, screening effect). Moreover, the current Mt- and asbestos-related research is not free from bias. This is, predominately due to industrial interests, particularly the promotion of chrysotile interfering with objectivity in some studies 
[90]. The quality of research and reviewing should be taken into account defining inclusion criteria for studies into meta-analyses and systematic reviews. It seems that some voluminous papers are contributing more to the tangling than to clarifying the problem. A possible solution could be large-scale chronic bioassays including larger animals and primates [91]. Among others, such experiments may help to identify an actual "no-effect" or threshold exposure levels for different fibers. The bioassays with fiber inhalation, comparable to exposures in the asbestos industry, can be organized e.g. in stray animal shelters and breeding facilities for primates without application of invasive methods. Sine qua non conditions of animal experimentation must be objectivity and integrity.

The conclusion of the WHO and IARC assessments is that chrysotile causes cancer of the lung, mesothelioma and asbestosis [85]. Different asbestos types can be mixed in the international trade [92]. As mentioned above, carcinogenic effect depends not only on biopersistence but also on fiber dimensions notwithstanding fiber type $[10,65,66,93]$, which is an additional argument in favor of the a priori "all fibers equal" approach to different types of asbestos and its substitutes. Admittedly, it is possible that the difference in toxicity between the amphiboles and chrysotile is so considerable that it must be reflected in regulations. In the author's opinion, the "all fibers equal" basis of official regulations can be accepted provisionally, pending objective and reliable evidence. It would be not only a technically most plausible solution, but also partly compatible with current, albeit conflicting, knowledge. Considering the strong economic interests behind the research comparing toxicity of different asbestos types [94], any deviations from the "all fibers equal" [95] concept must be based on high-quality, independent research.

\section{Conclusion}

Current asbestos-related regulations are irrational. Asbestos production and trade is prohibited in some countries, while others have maintained or increased production and use in recent years. Substitution of asbestos by artificial fibers would not necessarily lower or eliminate health risks [10-13,96,97]. The increased incidence of malignant $\mathrm{Mt}$ in developed nations $[98,99]$, despite the prohibition of asbestos, is probably at least in part due to improved diagnostics, an increasing awareness of $\mathrm{Mt}$, a screening effect in asbestos-exposed populations, and some over-diagnosis in conditions with an unclear demarcation of malignant $\mathrm{Mt}$ as an entity. This screening effect has probably contributed to an increased registered incidence of all asbestos-related diseases in exposed populations, and a resultant over-estimation of dose-response relationships particularly after low-dose exposures. On the basis of independent scientific data, the bans and restrictions on asbestos in some countries should therefore be re-examined and potentially revised. Any permit of continued production or use of asbestos materials must be accompanied by regulations and efficient measures to prevent environmental contamination, domestic or passive exposures, associated even with minimal additional risk.

\section{References}

1. Komis CJ, Scott B (1990) The regulatory framework-occupational safety and health administration. In: Benarde MA (ed). The hazardous fiber. CRC Press: Boca Raton, pp. 295-320.

2. ATSDR (2014) Asbestos Toxicity. What Are U.S. Standards and Regulations for Asbestos Levels? Agency for Toxic Substances and Disease Registry. Atlanta, Georgia.

3. Farrell P (2014) Mr Fluffy: the cancerous legacy hidden in hundreds of Canberra homes. The Guardian.

4. Krasovskii GN, Mozhaev EA (1993) Asbestos in drinking water (review). Gig Sanit 20-22.

5. Casali M, Carugno M, Cattaneo A, Consonni D, Mensi C et al. (2015) Asbestos lung burden in necroscopic samples from the general population of Milan, Italy. Ann Occup Hyg 59: 909-921.

6. Bayram M, Bakan ND (2014) Environmental exposure to asbestos: from geology to mesothelioma. Curr Opin Pulm Med 20: 301-307.

7. Jargin SV (2014) On the genetic effects of low-dose radiation. J Environ Occup Sci 3: 199-203.

8. Jargin SV (2015) Hormesis and homeopathy: The artificial twins. J Intercult Ethnopharmacol 4: 74-77.

9. Pierce JS, McKinley MA, Paustenbach DJ, Finley BL (2008) An evaluation of reported no-effect chrysotile asbestos exposures for lung cancer and mesothelioma. Crit Rev Toxicol 38: 191-214.

10. Donaldson K, Poland CA, Murphy FA, MacFarlane M, Chernova T, et al. (2013) Pulmonary toxicity of carbon nanotubes and asbestos - similarities and differences. Adv Drug Deliv Rev 65: 2078-2086.

11. Greim H, Utell MJ, Maxim LD, Niebo R (2014) Perspectives on refractory ceramic fiber (RCF) carcinogenicity: comparisons with other fibers. Inhal Toxicol 26: 789-810.

12. Utell MJ, Maxim LD (2010) Refractory ceramic fiber (RCF) toxicity and epidemiology: a review. Inhal Toxicol 22: 500-521.

13. Røe OD, Stella GM (2015) Malignant pleural mesothelioma: history, controversy and future of a manmade epidemic. Eur Respir Rev 24: 115-131.

14. Røe OD, Anderssen E, Helge E, Pettersen CH, Olsen KS, et al. (2009) Genome-wide profile of pleural mesothelioma versus parietal and visceral pleura: the emerging gene portrait of the mesothelioma phenotype. PLoS One 4: e6554.

15. Tomasetti M, Amati M, Santarelli L, Alleva R, Neuzil J (2009) Malignant mesothelioma: biology, diagnosis and therapeutic approaches. Curr Mol Pharmacol 2: 190-206

16. Jasani B, Gibbs A (2012) Mesothelioma not associated with asbestos exposure. Arch Pathol Lab Med 136: 262-267.

17. Carbone M, Ly BH, Dodson RF, Pagano I, Morris PT, et al. (2012) Malignant mesothelioma: facts, myths, and hypotheses. J Cell Physiol 227: 44-58.

18. International Agency for Research on Cancer (2012) Asbestos (chrysotile, amosite, crocidolite, tremolite, actinolite, and anthophyllite). In: Arsenic, Metals, Fibres and Dusts. IARC Monographs on the Evaluation of Carcinogenic Risks to Humans 100C.

19. Panou V, Vyberg M, Weinreich UM, Meristoudis C, Falkmer UG, et al. (2015) The established and future biomarkers of malignant pleural mesothelioma. Cancer Treat Rev 41: 486-495.

20. Kerger BD, James RC, Galbraith DA (2014) Tumors that mimic asbestosrelated mesothelioma: Time to consider a genetics-based tumor registry? Front Genet 5: 151

21. Husain AN, Colby TV, Ordóñez NG, Krausz T, Borczuk A, et al. (2009) Guidelines for pathologic diagnosis of malignant mesothelioma: a consensus statement from the International Mesothelioma Interest Group. Arch Pathol Lab Med 133: 1317-1331

22. Musti M, Kettunen E, Dragonieri S, Lindholm P, Cavone D, et al. (2006) Cytogenetic and molecular genetic changes in malignant mesothelioma. Cancer Genet Cytogenet 170: 9-15

23. Lindholm PM, Salmenkivi K, Vauhkonen H, Nicholson AG, Anttila S, et al. (2007) Gene copy number analysis in malignant pleural mesothelioma using oligonucleotide array CGH. Cytogenet Genome Res 119: 46-52. 
24. van der Bij S, Schaake E, Koffijberg H, Burgers JA, de Mol BA, et al. (2011) Markers for the non-invasive diagnosis of mesothelioma: a systematic review. Br J Cancer 104: 1325-1333.

25. Hollevoet K, Nackaerts K, Thimpont J, Germonpré P, Bosquée L, et al. (2010) Diagnostic performance of soluble mesothelin and megakaryocyte potentiating factor in mesothelioma. Am J Respir Crit Care Med 181: 620625.

26. Cristaudo A, Foddis R, Vivaldi A, Guglielmi G, Dipalma N, et al. (2007) Clinical significance of serum mesothelin in patients with mesothelioma and lung cancer. Clin Cancer Res 13: 5076-5081.

27. Park EK, Sandrini A, Yates DH, Creaney J, Robinson BW, et al. (2008) Soluble mesothelin-related protein in an asbestos-exposed population: the dust diseases board cohort study. Am J Respir Crit Care Med 178: 832-837.

28. Creaney J, Dick IM, Robinson BW (2015) Discovery of new biomarkers for malignant mesothelioma. Curr Pulmonol Rep 4: 15-21.

29. Grigoriu BD, Scherpereel A, Devos P, Chahine B, Letourneux M, et al. (2007) Utility of osteopontin and serum mesothelin in malignant pleural mesothelioma diagnosis and prognosis assessment. Clin Cancer Res 13: 2928-2935.

30. Gee GV, Koestler DC, Christensen BC, Sugarbaker DJ, Ugolini D, et al. (2010) Downregulated microRNAs in the differential diagnosis of malignan pleural mesothelioma. Int J Cancer 127: 2859-2869.

31. Reid G (2015) MicroRNAs in mesothelioma: from tumour suppressors and biomarkers to therapeutic targets. J Thorac Dis 7: 1031-1040.

32. Truini A, Coco S, Alama A, Genova C, Sini C, et al. (2014) Role of microRNAs in malignant mesothelioma. Cell Mol Life Sci 71: 2865-2878.

33. Sheff KW, Hoda MA, Dome B, Hegedus B, Klepetko W, et al. (2012) The role of microRNAs in the diagnosis and treatment of malignant pleura mesothelioma--a short review. Microrna 1: 40-48.

34. Jargin SV (2014) Renal biopsy for research: an overview of Russian experience. J Interdiscipl Histopathol 2: 88-95.

35. Yang H, Testa JR, Carbone M (2008) Mesothelioma epidemiology, carcinogenesis, and pathogenesis. Curr Treat Options Oncol 9: 147-157.

36. Elovskaia LT (1997) Anti-asbestos campaign and conference on "Asbestos and health issues". Med Tr Prom Ekol 16-21.

37. Izmerov NF, Kovalevskii EV (2004) Regulations of controlled use of asbestoscontaining materials in construction industry. Med Tr Prom Ekol 5-12.

38. Kogan FM (1995) Modern concept of asbestos safety. ARGO: Ekaterinburg.

39. Neiman SM, Vezentsev AI, Kashanskii SV (2006) About safety of asbestos cement materials and products. Stroimaterialy: Moscow.

40. Izmerov NF (2008) WHO and ILO Program on elimination of asbestos-related diseases. Med Tr Prom Ekol 1-8.

41. Bernstein DM (2014) The health risk of chrysotile asbestos. Curr Opin Pulm Med 20: 366-370.

42. Bernstein DM, Rogers R, Smith $P$ (2004) The biopersistence of brazilian chrysotile asbestos following inhalation. Inhal Toxicol 16: 745-761.

43. Sebastien P, Janson X, Gaudichet A, Hirsch A, Bignon J (1980) Asbestos retention in human respiratory tissues: Comparative measurements in lung parenchyma and in parietal pleura. IARC Sci Publ 237-246.

44. Nicholson WJ (1991) Comparative dose-response relationships of asbestos fiber types: magnitudes and uncertainties. Ann N Y Acad Sci 643: 74-84.

45. Kohyama N, Suzuki Y (1991) Analysis of asbestos fibers in lung parenchyma, pleural plaques, and mesothelioma tissues of North American insulation workers. Ann N Y Acad Sci 643: 27-52.

46. Stayner LT, Dankovic DA, Lemen RA (1996) Occupational exposure to chrysotile asbestos and cancer risk: a review of the amphibole hypothesis. Am J Public Health 86: 179-186.

47. Coin PG, Roggli VL, Brody AR (1994) Persistence of long, thin chrysotile asbestos fibers in the lungs of rats. Environ Health Perspect 102: 197-199.
48. Suzuki Y, Yuen SR (2002) Asbestos fibers contributing to the induction of human malignant mesothelioma. Ann N Y Acad Sci 982: 160-176.

49. Currie GP, Watt SJ, Maskell NA (2009) An overview of how asbestos exposure affects the lung. BMJ 339: b3209.

50. Smith AH, Wright CC (1996) Chrysotile asbestos is the main cause of pleura mesothelioma. Am J Ind Med 30: 252-266.

51. Dodson RF, Williams MG Jr, Corn CJ, Brollo A, Bianchi C (1990) Asbestos content of lung tissue, lymph nodes, and pleural plaques from former shipyard workers. Am Rev Respir Dis 142: 843-847.

52. Gibbs AR, Stephens M, Griffiths DM, Blight BJ, Pooley FD (1991) Fibre distribution in the lungs and pleura of subjects with asbestos related diffuse pleural fibrosis. Br J Ind Med 48: 762-770.

53. Boutin C, Dumortier P, Rey F, Viallat JR, De Vuyst P (1996) Black spots concentrate oncogenic asbestos fibers in the parietal pleura. Thoracoscopic and mineralogic study. Am J Respir Crit Care Med 153: 444-449.

54. Sekido Y (2013) Molecular pathogenesis of malignant mesothelioma Carcinogenesis 34: 1413-1419.

55. Bernstein D, Dunnigan J, Hesterberg T, Brown R, Velasco JA, et al. (2013) Health risk of chrysotile revisited. Crit Rev Toxicol 43: 154-183.

56. Pezerat $\mathrm{H}$ (2009) Chrysotile biopersistence: the misuse of biased studies. Int J Occup Environ Health 15: 102-106.

57. Larsen G (1989) Experimental data on in vitro fibre solubility. IARC Sci Pub 134-139.

58. Harington JS (1991) The carcinogenicity of chrysotile asbestos. Ann N Y Acad Sci 643: 465-472.

59. Hesterberg TW, Barrett JC (1984) Dependence of asbestos- and mineral dust-induced transformation of mammalian cells in culture on fiber dimension. Cancer Res 44: 2170-2180.

60. Wagner JC, Berry G, Skidmore JW, Timbrell V (1974) The effects of the inhalation of asbestos in rats. Br J Cancer 29: 252-269.

61. Wagner JC (1975) Proceedings: Asbestos carcinogenesis. Br J Cancer 32 258-259.

62. Berman DW, Crump KS, Chatfield EJ, Davis JM, Jones AD (1995) The sizes, shapes, and mineralogy of asbestos structures that induce lung tumors or mesothelioma in AF/HAN rats following inhalation. Risk Anal 15: 181-195.

63. Landrigan PJ, Nicholson WJ, Suzuki Y, Ladou J (1999) The hazards of chrysotile asbestos: a critical review. Ind Health 37: 271-280.

64. Davis JM, Beckett ST, Bolton RE, Collings P, Middleton AP (1978) Mass and number of fibres in the pathogenesis of asbestos-related lung disease in rats. $\mathrm{Br}$ J Cancer 37: 673-688.

65. (1996) Consensus report. International Agency for Research on Cancer Mechanisms of fiber carcinogenesis. IARC Sci Publ 1-9.

66. Berman DW, Crump KS (2008) A meta-analysis of asbestos-related cance risk that addresses fiber size and mineral type. Crit Rev Toxicol 38 Suppl 1: 49-73.

67. Finkelstein MM (2103) Letter to the Editor re Bernstein et al: Health risk of chrysotile revisited. Crit Rev Toxicol, 2013; 43: 154-183. Crit Rev Toxicol 43: 707-708.

68. Rogers AJ, Leigh J, Berry G, Ferguson DA, Mulder HB, et al. (1991) Relationship between lung asbestos fiber type and concentration and relative risk of mesothelioma. A case-control study. Cancer 67: 1912-1920.

69. Dufresne A, Bégin R, Massé S, Dufresne CM, Loosereewanich $\mathrm{P}$, et al (1996) Retention of asbestos fibres in lungs of workers with asbestosis, asbestosis and lung cancer, and mesothelioma in Asbestos township. Occup Environ Med 53: 801-807.

70. Finkelstein MM, Dufresne A (1999) Inferences on the kinetics of asbestos deposition and clearance among chrysotile miners and millers. Am J Ind Med 35: 401-412. 
Citation: Jargin SV. Asbestos-Related Research: First Objectivity then Conclusions. J Environ Stud. 2015;1(1): 6.

71. Bernstein D, Dunnigan J, Hesterberg T, Brown R, Legaspi Velasco JA, et al. (2013) Response to Murray M. Finkelstein, letter to the editor re Bernstein et al: Health risk of chrysotile revisited. Crit Rev Toxicol, 2013; 43(2): 154-183. Crit Rev Toxicol 43: 709-710.

72. Loomis D, Dement JM, Wolf SH, Richardson DB (2009) Lung cancer mortality and fibre exposures among North Carolina asbestos textile workers. Occup Environ Med 66: 535-542.

73. Frank AL, Dodson RF, Williams MG (1998) Carcinogenic implications of the lack of tremolite in UICC reference chrysotile. Am J Ind Med 34: 314-317.

74. Mirabelli D, Calisti R, Barone-Adesi F, Fornero E, Merletti F, et al. (2008) Excess of mesotheliomas after exposure to chrysotile in Balangero, Italy Occup Environ Med 65: 815-819.

75. Egilman D, Menéndez LM (2011) A case of occupational peritoneal mesothelioma from exposure to tremolite-free chrysotile in Quebec, Canada: A black swan case. Am J Ind Med 54: 153-156.

76. Kanarek MS (2011) Mesothelioma from chrysotile asbestos: update. Ann Epidemiol 21: 688-697.

77. Wagner JC (1997) Asbestos-related cancer and the amphibole hypothesis The first documentation of the association. Am J Public Health 87: 687-688.

78. Stayner LT, Dankovic DA, Lemen RA (1997) Asbestos-related cancer and the amphibole hypothesis: 2. Stayner and colleagues respond. Am J Pub Health 87: 688

79. Hansen J, de Klerk NH, Musk AW, Hobbs MS (1998) Environmental exposure to crocidolite and mesothelioma: exposure-response relationships. Am J Respir Crit Care Med 157: 69-75.

80. Jargin SV (2015) Solid cancer increase among Chernobyl liquidators: alternative explanation. Radiat Environ Biophys 54: 373-375.

81. Berry G, Reid A, Aboagye-Sarfo P, de Klerk NH, Olsen NJ, et al. (2012) Malignant mesotheliomas in former miners and millers of crocidolite at Wittenoom (Western Australia) after more than 50 years follow-up. $\mathrm{Br} J$ Cancer 106: 1016-1020.

82. Musk AW, de Klerk NH, Reid A, Ambrosini GL, Fritschi L, et al. (2008) Mortality of former crocidolite (blue asbestos) miners and millers at Wittenoom. Occup Environ Med 65: 541-543.

83. Reid A, Heyworth J, de Klerk NH, Musk B (2008) Cancer incidence among women and girls environmentally and occupationally exposed to blue asbestos at Wittenoom, Western Australia. Int J Cancer 122: 2337-2344.

84. de Klerk N, Alfonso H, Olsen N, Reid A, Sleith J, et al. (2013) Familial aggregation of malignant mesothelioma in former workers and residents of
Wittenoom, Western Australia. Int J Cancer 132: 1423-1428.

85. World Health Organization (2014) Chrysotile Asbestos. WHO Press: Geneva

86. Yarborough CM (2007) The risk of mesothelioma from exposure to chrysotile asbestos. Curr Opin Pulm Med 13: 334-338.

87. McDonald JC (2010) Epidemiology of malignant mesothelioma -an outline Ann Occup Hyg 54: 851-857.

88. Hodgson JT, Darnton A (2000) The quantitative risks of mesothelioma and lung cancer in relation to asbestos exposure. Ann Occup Hyg 44: 565-601.

89. Hodgson JT, Darnton A (2010) Mesothelioma risk from chrysotile. Occup Environ Med 67: 432

90. Baur X, Soskolne CL, Lemen RA, Schneider J, Woitowitz HJ, et al. (2015) How conflicted authors undermine the World Health Organization (WHO) campaign to stop all use of asbestos: spotlight on studies showing that chrysotile is carcinogenic and facilitates other non-cancer asbestos-related diseases. Int J Occup Environ Health 37: 176-179.

91. Gwinn MR, DeVoney D, Jarabek AM, Sonawane B, Wheeler J, et al. (2011) Meeting report: mode(s) of action of asbestos and related mineral fibers. Environ Health Perspect 119: 1806-1810.

92. Tossavainen A, Kotilainen M, Takahashi K, Pan G, Vanhala E (2001) Amphibole fibres in Chinese chrysotile asbestos. Ann Occup Hyg 45: 145152.

93. Roggli VL (2015) The so-called short-fiber controversy: Literature review and critical Analysis. Arch Pathol Lab Med 139: 1052-1057.

94. Tweedale G, McCulloch J (2004) Chrysophiles versus chrysophobes: The white asbestos controversy, 1950s-2004. Isis 95: 239-259.

95. Jargin SV (2013) Russian opinion on asbestos: All fibers equal. Environ Eco Res 1: 79-83.

96. van Berlo D, Clift MJ, Albrecht C, Schins RP (2012) Carbon nanotubes: an insight into the mechanisms of their potential genotoxicity. Swiss Med Wkly 142: w13698.

97. Toyokuni S (2013) Genotoxicity and carcinogenicity risk of carbon nanotubes Adv Drug Deliv Rev 65: 2098-2110.

98. Zervos MD, Bizekis C, Pass HI (2008) Malignant mesothelioma 2008. Curr Opin Pulm Med 14: 303-309.

99. Murayama T, Takahashi K, Natori Y, Kurumatani N (2006) Estimation of future mortality from pleural malignant mesothelioma in Japan based on an age-cohort model. Am J Ind Med 49: 1-7. 